\title{
Education and Outreach in the Life Sciences - Crosswalk Analysis Report: Survey and Focus Group Findings
}

RL Burbank (PNNL)

LV John (Battelle)

HA Mahy (PNNL)
S Wijesinha Rose (Battelle)

RE Weller (PNNL)

A Nelson-Wally (Battelle)

October 2008

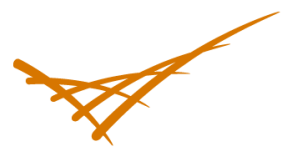

Pacific Northwest

NATIONAL LABORATORY

Proudly Operated by Battelle Since 1965 


\title{
DISCLAIMER
}

This report was prepared as an account of work sponsored by an agency of the United States Government. Neither the United States Government nor any agency thereof, nor Battelle Memorial Institute, nor any of their employees, makes any warranty, express or implied, or assumes any legal liability or responsibility for the accuracy, completeness, or usefulness of any information, apparatus, product, or process disclosed, or represents that its use would not infringe privately owned rights. Reference herein to any specific commercial product, process, or service by trade name, trademark, manufacturer, or otherwise does not necessarily constitute or imply its endorsement, recommendation, or favoring by the United States Government or any agency thereof, or Battelle Memorial Institute. The views and opinions of authors expressed herein do not necessarily state or reflect those of the United States Government or any agency thereof.

\author{
PACIFIC NORTHWEST NATIONAL LABORATORY \\ operated by \\ BATTELLE \\ for the \\ UNITED STATES DEPARTMENT OF ENERGY \\ under Contract DE-AC05-76RL01830 \\ Printed in the United States of America \\ Available to DOE and DOE contractors from the \\ Office of Scientific and Technical Information, \\ P.O. Box 62, Oak Ridge, TN 37831-0062; \\ ph: (865) 576-8401 \\ fax: $(865) 576-5728$ \\ email: reports@adonis.osti.gov
}

Available to the public from the National Technical Information Service

5301 Shawnee Rd., Alexandria, VA 22312 ph: (800) 553-NTIS (6847)

email: orders@ntis.gov <http://www.ntis.gov/about/form.aspx>

Online ordering: http://www.ntis.gov

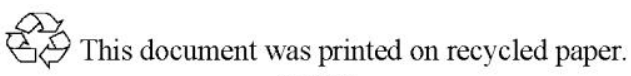

(8/2010) 


\section{Education and Outreach in the Life Sciences - Crosswalk Analysis Report: Survey and Focus Group Findings}

RL Burbank (PNNL)

LV John (Battelle)

HA Mahy (PNNL)
S Wijesinha Rose (Battelle)

RE Weller (PNNL)

A Nelson-Wally (Battelle)

October 2008

Prepared for

the U.S. Department of Energy

under Contract DE-AC05-76RL01830

Pacific Northwest National Laboratory

Richland, Washington 99352 




\section{Contents}

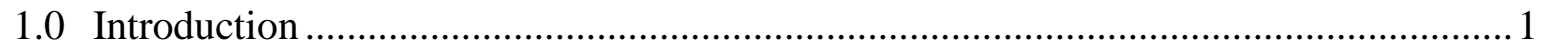

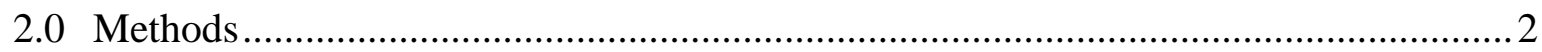

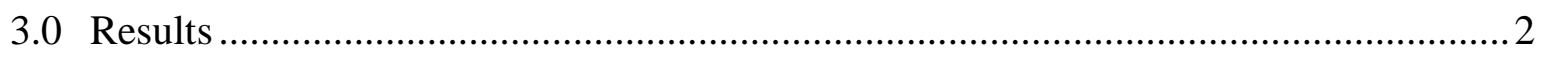

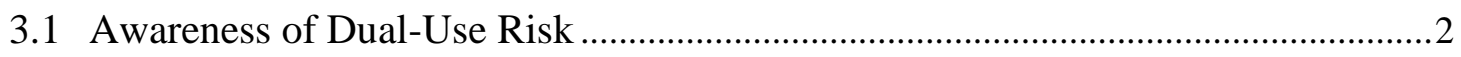

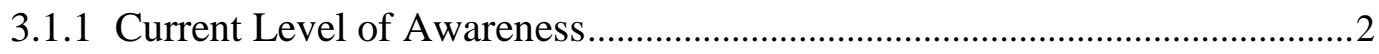

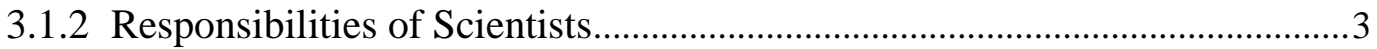

3.2 Factors that Influence Changes in Awareness or Changes in Behavior ..................4

3.3 Codes of Conduct and Guidelines ......................................................................

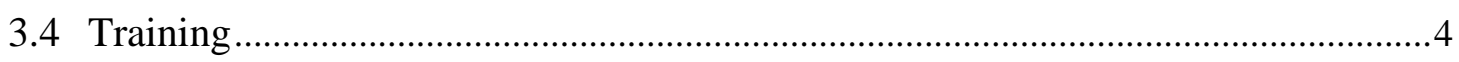

3.4.1 Perceived Need for Training .................................................................

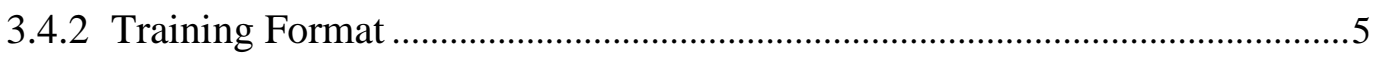

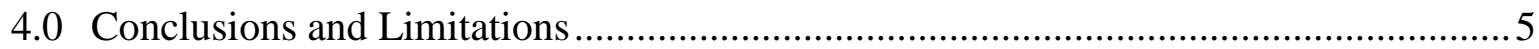




\subsection{Introduction}

Rapid developments in biotechnology and the life sciences bring significant benefits, but also create new security challenges. In recent years, members of the scientific and security policy communities have raised concerns about the potential for misuse of knowledge, tools, and techniques for purposes of bioterrorism. Such research is sometimes called "dual-use" research because, although the research is intended for beneficial purposes only, it could be misapplied. The role of scientists, institutions, scientific societies, and the government is critical in fostering an environment that enhances both the scientific enterprise and national security.

In 2004, the U.S. government established the National Science Advisory Board on Biosecurity (NSABB) under the auspices of the National Institutes of Health to contemplate the possibility and impact of greater oversight for life sciences research to prevent or mitigate deliberate misuse. Similarly, the U.S. Department of Energy (DOE) is considering how to respond to emerging issues of concern related to dual-use. Other Federal agencies are planning to issue further guidelines and considering additional policies regarding responsible scientific research. Discussion sessions on this topic were also conducted by Pacific Northwest National Laboratory (PNNL) for the DOE's Office of International Regimes and Agreements (NA-243) at nine of the national laboratories in Fall of 2006.

The DOE's National Nuclear Security Agency (NNSA) asked PNNL to consider the role of individual scientists in upholding safety and security. The views of scientists were identified as a critical component of this policy process. Therefore, scientists, managers, and representatives of Institutional Biosafety Committees (IBCs) at the national labs were invited to participate in a brief web-based survey that was designed to:

- Evaluate the function of the 2006 outreach and education seminars that were conducted by the U.S. DOE.

- Assess the opinions of scientists about potential future mechanisms to address dual-use concerns in the life sciences community.

- Gather data on scientists' attitudes toward potential security risks from agricultural, public health, and biomedical research.

- Give scientists a voice in the policy-making process.

In addition, three focus groups were conducted with scientists, managers, and IBC representatives to discuss some of the questions related to education, outreach, and codes of conduct in further detail and gather additional input on biosecurity and dual-use awareness at the laboratories. The overall purpose of this process was to identify concerns related to these topics and to gather suggestions for creating an environment where both the scientific enterprise and national security are enhanced.

The information gathered through the survey and focus groups will be instrumental in informing the U.S. position at the Biological Weapons Convention (BWC) Experts' Group meeting in August 2008, as well as in moving toward a sustainable mechanism for biosecurity education and awareness. The information will also guide DOE action in developing educational tools that will help promote a laboratory culture of responsibility. 


\subsection{Methods}

To recruit individuals for the web survey and the focus groups, the PNNL Project Director sent email invitations to individuals who participated in the 2006 Outreach and Education Training and other points of contact at each of the national laboratories $(\mathrm{N}=202)$. Of these invitations, 173 were delivered and 29 were returned as undeliverable. The web survey email invitation introduced the purpose of the survey and invited individuals to participate by clicking on a hyperlink. Individuals were also encouraged to forward the survey link to others who might be interested in participating. Several follow-up emails were sent to the entire sample encouraging participation. After removing two cases with incomplete responses for most of the survey questions, the final sample from the web survey consisted of 47 respondents.

The focus group email invitation described the purpose of the focus groups and invited individuals to participate in a focus group for managers, scientists, or IBC representatives. Each of these groups was offered a choice of times, and the date and time that was convenient for the majority of individual participants was selected for each of the three groups. Additional follow-up emails were sent to points of contact at each of the laboratories to encourage participation. The following table summarizes the final focus group participation.

\begin{tabular}{|l|c|c|l|}
\hline \multicolumn{1}{|c}{ Focus Group Type } & \multicolumn{1}{c}{ Date } & $\begin{array}{c}\text { \# of } \\
\text { Participants }\end{array}$ & \multicolumn{1}{c|}{ Labs Represented } \\
\hline Scientists & June 11, 2008 & 5 & $\begin{array}{l}\text { Brookhaven, Los Alamos, Oak } \\
\text { Ridge, PNNL }\end{array}$ \\
\hline Managers & June 12, 2008 & 5 & Idaho, Los Alamos, NREL, PNNL \\
\hline IBC representatives & June 18, 2008 & 5 & $\begin{array}{l}\text { Berkeley, Los Alamos, Oak } \\
\text { Ridge, Sandia }\end{array}$ \\
\hline
\end{tabular}

In addition, comments provided by three individuals who were not available to attend the IBC focus group were integrated into the analysis.

\subsection{Results}

This report provides cross-cutting findings from the survey and focus groups results. In particular we highlight areas of convergence across these two methodologies and describe how the results from these two methods complement each other.

\subsection{Awareness of Dual-Use Risk}

\subsubsection{Current Level of Awareness}

Survey results found that about half of the participants considered that they were currently conducting or managing research with dual-use potential $(50 \%)$, while slightly over half reported that they had worked with or managed research using select agents (57\%) at some point. Very few participants were currently conducting or managing research that included the types of experiments anticipated as needed special review under NSABB guidelines (4\%). 
Survey results showed that most participants were familiar with the Biological Weapons Convention (89\%); fewer participants were familiar with the provisions of the BWC for biosafety and biosecurity (63\%) or with BWC Article IV as it introduces the concept of individual responsibility for upholding and promoting nonproliferation obligations (64\%). The survey also found that those respondents who had conducted select agent research were generally more aware of the BWC $(100 \%$ versus $75 \%)$, its provisions for biosecurity and biosafety (65\% versus 45\%), and Article IV (69\% versus 60\%) than were those who had not conducted such research.

These survey findings reflected the consensus among focus group participants on this topic. Consistently, focus group participants thought there would be greatest awareness of dual-use issues among those conducting research with a perceived "high" risk for dual-use potential versus those conducting research with lower risk. Individuals who were generally considered to be more aware of dual-use considerations included those conducting work with select agents or with with organisms at higher than Biosafety Level 2 (BSL2) rating, or those working for national security clients.

\subsubsection{Responsibilities of Scientists}

Survey respondents were asked to assess the possibility that several types of actions by scientists or institutions would minimize the potential threat to national security posed by dual-use research. Survey findings indicate general support for the idea that if scientists conduct a review of their own work for dual-use considerations (79\% agree or strongly agree) or provide formal assurance to their institution that they were conducting such an assessment (60\% agree or strongly agree) it would serve to minimize potential threat. In addition, there was slightly higher agreement $(47 \%)$ than disagreement $(43 \%)$ with the view that research review by an appropriate individual or board (such as an IBC) would help to mitigate risk and that classifying research findings on dual-use could minimize the potential threat (46\% agree/strongly agree versus $31 \%$ disagree/strongly disagree).

Focus group participants were asked more generally about actions consistent with being a "responsible scientist" given the potential for dual use in the life sciences. Across groups there was support for the idea that Principal Investigators (PIs) had responsibility to review the potential for dual use in their own work. However, focus group participants also stressed that in the national laboratory context, minimizing risk related to potential dual use is actually a responsibility shared among the PI, the IBC, Institutional Review Boards (IRBs), the biosafety officer, the authorized derivative classifier (ADC), project managers and line managers that approve of proposals, and other institutional controls.

Survey respondents were split over whether placing some restrictions on the dissemination of research findings would help to minimize the potential threat posed by dual-use research. Similar percentages agreed versus disagreed with statements about placing restrictions on disclosure of research details through personal communication (37\% versus 39\%), altering or removing experimental methods or findings prior to publication or presentation (43\% versus 39\%), or restricting the publication of findings based on dual-use potential (36\% versus $41 \%)$.

These results were contradicted to some extent by the focus group respondents, whofelt that those conducting research with select agents or pathogens already took certain precautions against inappropriate publication of findings, and felt that additional restrictions were not necessary - or would be impossible to enforce and tend to hamper scientific research. In addition, for those conducting "low" risk research, scientists believed that, as long as common sense measures were followed, additional mandatory restrictions were unnecessary and potentially detrimental to advances in science. 


\subsection{Factors that Influence Changes in Awareness or Changes in Behavior}

A majority of survey respondents had participated in discussions about dual-use research and codes of conduct (68\%). Among these respondents, new or emerging guidelines addressing dual-use research, personal reading or research, and the 2006 Outreach and Education Training provided by PNNL staff were cited as drivers for these discussions. A percentage $(23 \%, \mathrm{~N}=11)$ of respondents also indicated that they had changed their behavior related to bioterrorism concerns in the last two years. Of these 11 respondents, most of the types of changes made related to how information is disseminated through personal communication, conference presentations, or modification of a manuscript; rather than through the avoidance of collaboration, conducting particular research, or providing information at all. Though cited by small numbers of respondents, the same set of factors - new or emerging guidelines, personal reading, and the 2006 training - were most often cited as contributing to behavioral changes. This underscores that, despite the basic safety and security measures in place at national laboratories, there is value to providing education related to dual-use.

Focus group participants were fairly evenly split between those who had observed an increase in awareness of dual use in their laboratory in the past few years versus those who had not seen a change. Factors most often cited by participants who had observed increased awareness included the 2006 Outreach and Education Training, issues in the popular media or publications of concern, discussion around proposals, or client directives or regulations regarding dual-use work.

\subsection{Codes of Conduct and Guidelines}

Survey participants were asked about their level of awareness of journal policies regarding potential dual use and their opinions about having guidelines for journals or codes of conduct for professional societies. Almost one-half of respondents (43\%) did not know about the proportion of journals requiring review regarding dual use. However, there was widespread agreement that journals should have such guidelines (83\% agree or strongly agree). Similarly, respondents were largely unaware about whether the professional societies to which they belonged had codes of conduct for members around dual use (44\%), but did agree with this idea ( $83 \%$ agree or strongly agree). Finally, survey respondents disagreed that providing greater Federal oversight of dual-use research would help to mitigate potential threat (61\% disagree or strongly disagree).

Focus group participants largely echoed these views. Those who had been journal reviewers reported that existing dual-use guidelines are sometimes inadequate, and some mentioned anecdotes of articles they have seen over the years that they thought had dual-use potential but that were nevertheless published in the peer-reviewed literature. Focus group participants were not specifically asked about professional society codes of conduct, although they did express the view that a mandatory code of conduct (such as from the Federal government) would be viewed as negative. However, some focus group participants did see value in voluntary guidelines or codes of conduct to clarify the scientific community consensus on what constitutes dual use and what scientists should be aware of in this arena.

\subsection{Training}

More than one-half of the survey respondents (57\%) participated in the 2006 Outreach and Education Training. The focus groups also included some individuals who had participated in the training. Both 
survey and focus groups respondents were asked about which groups may benefit from additional training in dual-use concerns and what training formats would be preferred.

\subsubsection{Perceived Need for Training}

Providing additional training on scientist obligations under the BWC, dual-use risks, and codes of conduct was seen as appropriate for a wide range of groups. Well over one-half of respondents saw the value of training for senior research scientists $(83 \%)$, program/project managers $(79 \%)$, IBC/IRB chairs and members (76\%), mid-level research scientists and laboratory managers (76\% each), and junior scientists $(60 \%)$. There was less support for training of research associates/technicians (36\%).

Approximately half of the respondents agreed that mandatory training by institutions for scientists would help to mitigate dual-use risk (51\% agree or strongly agree). A few respondents (6\%) did not see any need for additional training.

Focus group participants also noted the groups listed by survey participants as appropriate targets for additional training. In addition, they saw some value in training of trainees and interns, security officers, authorized derivative classifiers, and foreign nationals. A few scientist participants expressed the view that no additional training was needed.

Both survey respondents and focus group participants expressed the view that university students and researchers could benefit from additional training on and awareness of dual-use concerns. Survey respondents thought that such a move would help to reduce the risk that research may pose to national security (74\% agree or strongly agree). Focus group respondents cited universities as an area to target for training because of the perception that, since they operate under fewer restrictions than do the national laboratories, researchers in these settings were less aware of these issues. Training students early in these issues would be helpful as they begin their science careers.

\subsubsection{Training Format}

Survey respondents overwhelmingly preferred web-based training (81\%) to classroom training or a reference book ( $9 \%$ each). Focus group participants did not reach a consensus on the type of training format that would be most valuable. The two most frequently recommended formats were web-based training and in-person sessions, such as brown bags. In general, they saw web-based training as applicable to training for all or most staff, especially if content could be tiered based on the type of research conducted, while in-person sessions were seen as potentially more valuable for particular groups of staff, such as IBC members or managers who might have more specific concerns.

\subsection{Conclusions and Limitations}

The two methodologies - web survey and focus groups - were used to effectively obtain information about individuals' awareness of dual-use risks; perceptions of the need for training; and opinions about roles, responsibilities, and preventive measures related to life sciences research. In general, the survey and focus groups yielded similar results, with the focus group findings helping to inform the interpretation of the survey results. For example, both sets of results show variation in awareness of dual-use issues. Although the survey focused primarily on assessing the awareness of respondents themselves, the focus group protocol also asked respondents about their perceptions of the awareness levels of various key groups. Focus group respondents expressed the idea that levels of awareness may vary not only according to whether one is working with select agents, but also according to other parameters, such as whether one 
is working with national security clients versus on NIH-funded research. This type of subtle variation was best obtained via the open discussion format of a focus group. As another example, survey respondents were asked to select their most preferred training format and overwhelmingly selected a web-based approach, whereas focus group participants further indicated support for other types of training in different situations, particularly training sessions involving live discussion for topics that needed more indepth coverage.

The overlap of findings existed in other areas as well, with survey and focus group questions obtaining similar information in different ways. In the survey as in the focus group, respondents were asked to identify groups they thought should participate in training covering life sciences research risks. Similar groups of potential trainees were noted under both methodologies (e.g., scientists, managers, IBCs, university students). One benefit of having a list of groups for respondents to choose from in a survey is that it yields a distribution which can indicate whether some groups were considered to be in greater need of training than others. Factors influencing changes in behavior and awareness, as well as opinions about codes of conduct and guidelines, were comparable across the survey and focus group findings.

A common theme in the results of the survey and the focus groups was that additional mandatory restrictions on scientists and the dissemination of research were viewed as negative. This information was elicited differently in the two modes. In the web survey, respondents were asked to evaluate the effectiveness of certain actions in minimizing the potential threat to national security. Actions included: having Principal Investigators conduct initial evaluations of the dual-use potential of research, requiring certification for researchers conducting some dual-use research, and providing greater federal oversight of dual-use research.

In the focus groups, participants were asked about actions associated with being a responsible scientist when there is a possibility that the products or knowledge one generates could be misused. It is clear that individual respondents believe that scientists should act responsibly by evaluating their research for dualuse potential and taking precautions when discussing research or disseminating results. However, focus group findings suggest that most national laboratory researchers consider that they are already acting responsibly in this regard and that additional restrictions would restrict scientific progress. Neither surveys nor focus groups indicated that it additional regulations or oversight is necessary.

The study has several limitations that should be noted. First, both the survey and the focus groups addressed areas related to education, training, and information sharing. Participants were not asked to discuss other types of actions that could reduce the threat, or the value of education, etc. in relation to these other mechanisms.

Also, it is possible that the samples obtained for the web survey and focus groups do not reflect the general opinions of scientists, managers, and IBC representatives across the national laboratories. Focus group findings by their nature allow an in-depth look at the opinions of various groups but cannot be generalized to the entire population. In addition, the response rates for the survey are relatively low. Only about $27 \%$ of those who were delivered emails completed the web survey. Email was the primary mode of follow-up used to encourage participation, although some managers and points of contact at some laboratories did encourage staff in their groups to participate. Overall, it is likely that participants were self-selecting due to specific interest in the subject matter, which may skew results. This may mean that awareness is even lower than indicated by the survey and focus groups, that there is a relatively low level of concern regarding biosecurity, or that scientists do not want to engage in conversations about biosecurity (lack of time, concern about development of rules and regulations, etc.) 
Finally, the survey and focus group participants were drawn from the same pool of individuals, thus convergence between survey and focus group results should not be interpreted as the convergence of opinions across distinct groups.

Overall, however, the focus group and survey responses were largely comparable and provide valuable insight into the opinions and preferences of national laboratory scientists regarding training on dual-use research, the BWC, and codes of conduct. 


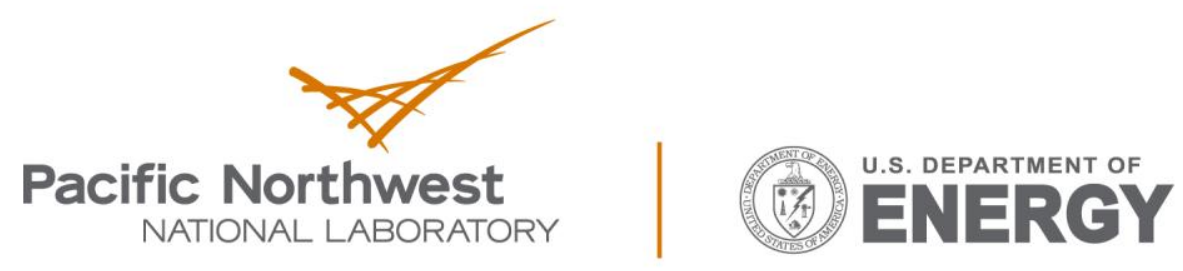

Proudly Operated by Battelle Since 1965

902 Battelle Boulevard

P.O. Box 999

Richland, WA 99352

1-888-375-PNNL (7665)

www.pnnl.gov 